\title{
Activation of activator protein 2 alpha by aspirin alleviates atherosclerotic plaque growth and instability in vivo
}

\author{
Jing-Jing Yang ${ }^{1}$, Peng Liं ${ }^{2}$, Fu Wang ${ }^{1}$, Wen-Jing Liang ${ }^{1}$, Hui Ma ${ }^{1}$, Yuan Chen ${ }^{1}$, Zhi- \\ Min Ma ${ }^{3}$, Quan-Zhong Li ${ }^{4}$, Qi-Sheng Peng ${ }^{5}$, Yun Zhang ${ }^{1}$ and Shuang-Xi Wang ${ }^{1,2}$ \\ ${ }^{1}$ Key Laboratory of Cardiovascular Remodeling and Function Research, Qilu Hospital, School of Medicine, Shandong \\ University, Jinan, China \\ 2 Department of Pharmacology, College of Pharmacy, Xinxiang Medical University, Xinxiang, China \\ ${ }^{3}$ Division of Endocrinology, The Second Affiliated Hospital, Soochow University, Suzhou, China \\ ${ }^{4}$ Division of Cardiology, The Affiliated Hospital, Guilin Medical University, Guilin, China \\ ${ }^{5}$ Key Laboratory for Zoonosis Research, Ministry of Education, Institute of Zoonosis, Jilin University, Changchun, China \\ Correspondence to: Shuang-Xi Wang, email: shuangxiwang@sdu.edu.cn \\ Yun Zhang, email: yunzhang@sdu.edu.cn \\ Keywords: activator protein 2a, aspirin, IkBa, atherosclerosis, Pathology Section \\ Received: March 24, $2016 \quad$ Accepted: June 17, $2016 \quad$ Published: July 04, 2016
}

\section{ABSTRACT}

\begin{abstract}
Aims: Aspirin has been used for the secondary prevention and treatment of cardiovascular disease for several decades. We investigated the roles of transcriptional factor activator protein $2 a(A P-2 a)$ in the beneficial effects of aspirin in the growth and vulnerability of atherosclerotic plaque. Methods and Results: In mice deficient of apolipoprotein $\mathrm{E}\left(\mathrm{Apoe}^{-/-}\right)$, aspirin $(20,50 \mathrm{mg} / \mathrm{kg} / \mathrm{day})$ suppressed the progression of atherosclerosis in aortic roots and increased the plaque stability in carotid atherosclerotic plaques induced by collar-placement. In vivo lentivirus-mediated RNA interference of AP-2a reversed the inhibitory effects of aspirin on atherosclerosis in Apoe $^{-/-}$mice. Mechanically, aspirin increased AP-2a phosphorylation and its activity, upregulated IkBa mRNA and protein levels, and reduced oxidative stress in cultured vascular smooth muscle cells. Furthermore, deficiency of AP-2a completely abolished aspirin-induced upregulation of IkBa levels and inhibition of oxidative stress in Apoe1- mice. Clinically, conventional doses of aspirin increased AP-2a phosphorylation and IkBa protein expression in humans subjects. Conclusion: Aspirin activates AP-2a to upregulate IkBa gene expression, resulting in attenuations of plaque development and instability in atherosclerosis.
\end{abstract}

\section{INTRODUCTION}

Atherosclerosis, formerly considered a bland lipid storage disease, actually involves an ongoing inflammatory response [1]. In the early stage of atherosclerosis, the abnormal homeostatic functions of the endothelium appear and promote an inflammatory response. Later in the process, increased inflammation stimulates enlargement of the plaque lesion weakening the protective fibrous cap of the atheroma [2], possibly leading to thrombosis and the occurrence of acute coronary syndrome.

Activating enhancer binding protein 2 alpha, also called activator protein $2 \alpha$ (AP-2 2 ), is a member of the AP-2 transcription factor family proteins consisting of $\alpha, \beta, \gamma, \delta$, and $\varepsilon$ subunits [3]. Mice deficient in AP-2 die after birth due to the abnormal skeletal and neural tube development, indicating a critical role of AP-2 in mammals $[4,5]$. AP- $2 \alpha$ recognizes the consensus DNA sequence of 5'-GCCNNNGGC-3' found in a number of genes involved in various cell functions [6]. The biological role and clinical relevance of AP- $2 \alpha$ in atherosclerosis have not been elucidated.

The ancient drug aspirin reduces the risks of cardiovascular disease (CVD) in part by its antiinflammatory and antiplatelet effects via the inhibition of cyclooxygenase (COX) enzymes [7]. The efficacy of aspirin for secondary prevention of CVD, such as atherosclerosis, is well established, but the benefit of 
aspirin for primary prevention is controversial [8-10].

Aspirin activates AMP-activated protein kinase (AMPK) in vascular cells [11-14]. Previously, we have shown that activation of AMPK increases AP- $2 \alpha$ phosphorylation in vascular smooth muscle cells (VSMC) and suppresses the formation of atherosclerotic plaques in mice [15-17]. Based on these studies, we hypothesize that aspirin induces AP- $2 \alpha$ phosphorylation leading to attenuation of the progression of atherosclerosis, including the growth and instability of plaque. In this study, we provided evidence that AP- $2 \alpha$ is crucial to the anti-inflammatory effects of aspirin that are independent of COX. Given the significant effects of aspirin-induced AP- $2 \alpha$ activation on plaque growth and stability, AP-2a may be an attractive target for the prevention of diseases related to the rupture of atherosclerotic plaques, such as stroke or myocardial infarction clinically.

\section{RESULTS}

\section{Aspirin attenuates the growth of atherosclerotic plaque in Apoe $^{-/}$mice}

Aspirin is used to reduce the risk of CVD in secondary prevention [18]. We firstly tested the doseresponse of aspirin $(5,20$, or $50 \mathrm{mg} / \mathrm{kg} / \mathrm{day})$ on the suppression of atherosclerotic lesion formation in Apoe $^{-/}$ mice fed a high fat diet for 8 weeks as described previously [19]. The atherosclerotic plaques in whole aortas (Figure $1 \mathrm{~A}, 1 \mathrm{~B}$ ) and aortic roots (Figure $1 \mathrm{C}-1 \mathrm{E}$ ) were determined by Oil Red staining or HE staining. As indicated in Figure $1 \mathrm{~A}-1 \mathrm{E}, 5 \mathrm{mg} / \mathrm{kg} /$ day aspirin did not reduce the size of atherosclerotic plaque, consistent with previous reports indicating that this dose of aspirin is ineffective
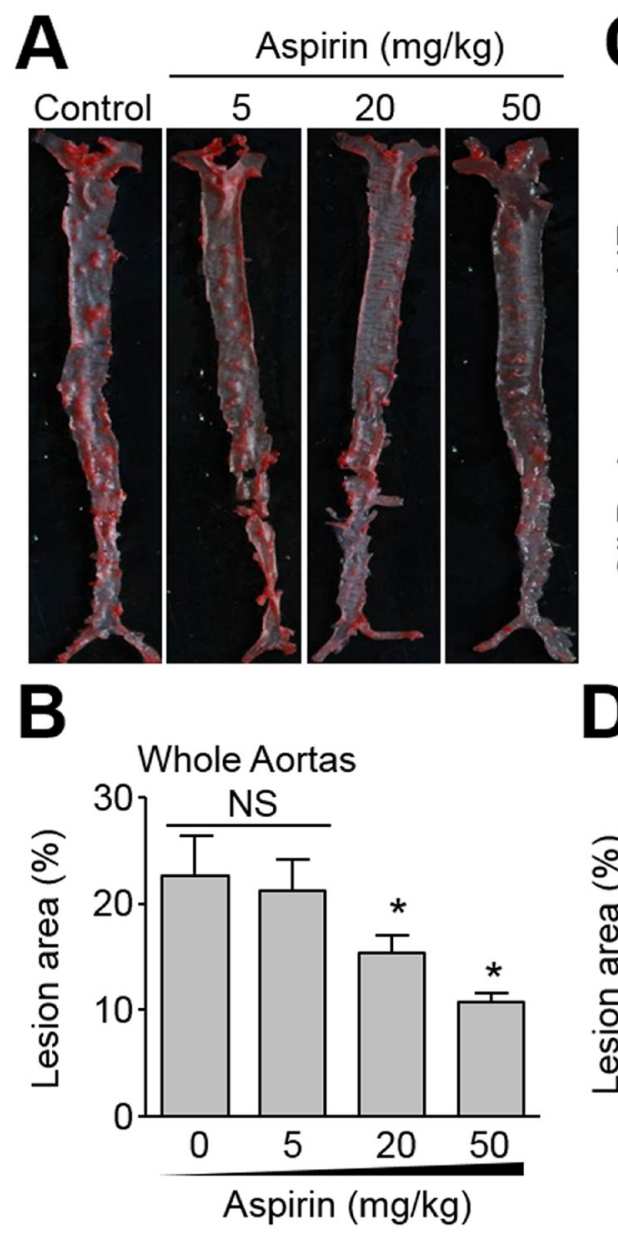
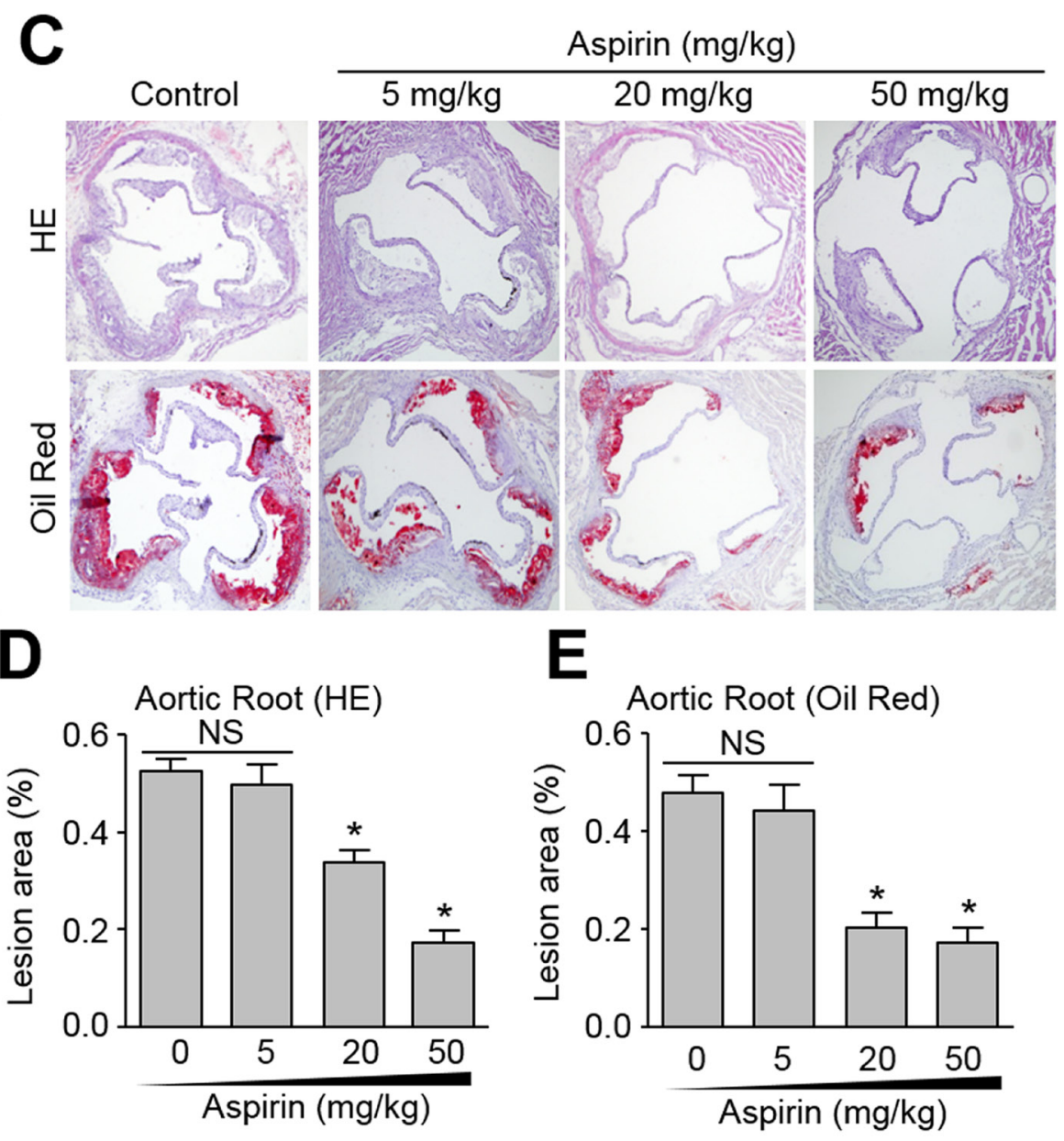

Figure 1: Effects of aspirin on aortic atherosclerotic plaque growth in Apoe $^{-/}$mice. The protocol and experimental designs were described in Supplementary Methods and Figure S1A. After 8-weeks of aspirin treatment, all mice were sacrificed under anaesthesia. A. The whole aortas including thoracic and abdominal aortas were collected for histological analysis of atherosclerosis by Oil Red staining of lipid deposition. B. Quantitative data of atherosclerotic lesion in the whole aortas. C. Histological analysis of aortic root by HE staining and Oil Red (original magnification X100). D. Quantitative analysis of atherosclerotic lesion size in aortic root by HE staining. E. Quantitative analysis of atherosclerotic lesion size in aortic root by Oil Red staining. $\mathrm{N}$ is $10-15$ in each group. ${ }^{*} P<0.05 v s$. Control (Aspirin at 0). NS indicates no significant difference. 
[9]. However, 20 and $50 \mathrm{mg} / \mathrm{kg} /$ day aspirin significantly decreased the size of atherosclerotic plaques in whole aortas and aortic roots, consistent with a recent report [20]. An aspirin dose response was evident with $50 \mathrm{mg} /$ $\mathrm{kg} /$ day aspirin substantially suppressing atherosclerotic formation compared to $20 \mathrm{mg} / \mathrm{kg} /$ day aspirin. These data indicate that aspirin has the potential to produce antiatherosclerotic effect in vivo.

\section{Aspirin increases the stability of atherosclerotic plaque in Apoe $^{-/}$mice}

In advanced atherosclerosis, rapture of instable atherosclerotic plaques contributes to a large number of victims of coronary heart disease [21]. Thus, we next examined the effects of aspirin on the stability of highrisk prone-to-rupture plaques. The carotid collar model of vulnerable plaque induction was performed in $\mathrm{Apoe}^{--}$ mice by placing a collar around the left common carotid artery and feeding the mice a high fat diet for 12 weeks as describe previously [22]. Aspirin was introduced into the drinking water from 4 to 12 weeks. HE staining of the left carotid artery revealed similar plaque lesion areas independent of aspirin treatment (Figure 2 and Supplementary Figure S1B), allowing atherosclerotic plaque stability to be evaluated. As shown in Figure 2 and Supplementary Figure S1C-S1F, aspirin at 20 or 50 $\mathrm{mg} / \mathrm{kg} /$ day, but not $5 \mathrm{mg} / \mathrm{kg} /$ day, significantly decreased the levels of infiltrating CD68 positive macrophages, Oil Red $\mathrm{O}$ staining, and increased expression of collagen and $\alpha$-smooth muscle actin ( $\alpha$-SMA) as indicators of VSMC and stability of carotid atherosclerotic plaques. Statistically, both doses of aspirin $(20,50 \mathrm{mg} / \mathrm{kg} /$ day $)$ decreased the plaque vulnerable index (Supplementary Figure S1G), which was calculated according to the ratio of area I $\left(\mathrm{Oil} \mathrm{Red}^{+}+\mathrm{CD} 68^{+}\right)$to area II $\left(\alpha-\mathrm{SMA}^{+}\right.$ + Collagen $\left.^{+}\right)$as described previously $[23,24] .50 \mathrm{mg} /$ $\mathrm{kg} /$ day aspirin was more effective than $20 \mathrm{mg} / \mathrm{kg}$ /day at maintaining the stability of vulnerable plaques. Our results suggests that aspirin increases plaque stability in advanced vulnerable atherosclerosis.

\section{Aspirin increases phosphorylation of AP-2 $\alpha$ in Apor $^{-/}$- mice}

Aspirin has been reported to activate AMPK [11]. Our previous studies revealed that AMPK directly phosphorylates AP-2 $\alpha$ at serine 219, an active form if it is phosphorylated [17]. Thus, we hypothesized that aspirin is able to activate AP- $2 \alpha$ via serine 219 phosphorylation. To test this notion, we determined the effects of aspirin on AP- $2 \alpha$ serine 219 phosphorylation in the carotid model of plaque development. As presented in Figure 2 and Supplementary Figure S1H, 20-50
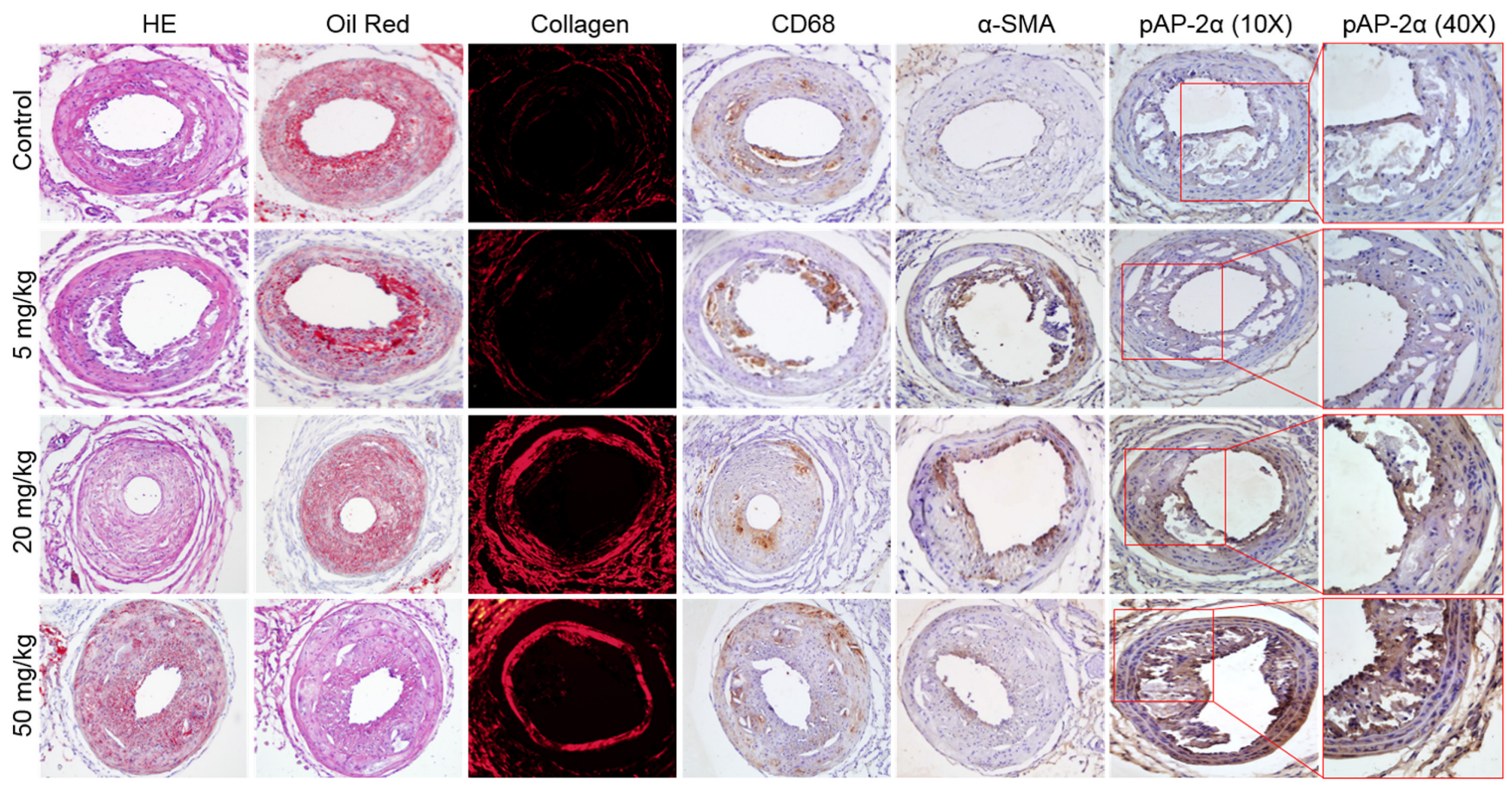

Figure 2: Effects of aspirin on carotid atherosclerotic plaque stability in $\boldsymbol{A p o e}^{-/-}$mice. The protocol and experimental designs were described in Supplementary Methods and Figure S1A. After 8-weeks of aspirin treatment, all mice were sacrificed under anaesthesia. Histological analysis of left common carotid arteries by HE staining, lipid content by Oil Red staining, collagen content by picrosirius red, and IHC analysis of CD68, $\alpha$-SMA, and phosphorylated AP-2 $\alpha$ (p AP-2 $\alpha$ ) (original magnification X100). 10-15 mice in each group. All quantitative data were shown in Supplementary Figure S1B-S1H. 
$\mathrm{mg} / \mathrm{kg} /$ day aspirin, but not $5 \mathrm{mg} / \mathrm{kg} /$ day, remarkably increased AP- $2 \alpha$ phosphorylation in vivo, supporting an important role of AP- $2 \alpha$ in the protective effects of aspirin on atherosclerosis. Since the effects of $50 \mathrm{mg} / \mathrm{kg} /$ day aspirin on atherosclerotic plaque stability and AP$2 \alpha$ phosphorylation were maximal, we chose $50 \mathrm{mg} / \mathrm{kg} /$ day as the optimal dose in most of the following animal experiments.

\section{Lentivirus-mediated RNA interfere of AP-2 $\alpha$ abolishes the suppressive effects of aspirin on atherosclerotic plaque growth in Apoe $^{-/-}$mice}

We next examined the roles of AP-2 $\alpha$ in the suppressive effects of aspirin on atherosclerosis in Apoe - $^{-1}$ mice. Due to the lethal phenotype of mice deficient in AP$2 \alpha$ [5], we generated AP- $2 \alpha-$ knockdown mice by infecting lentivirus containing AP-2 $\alpha$ short hairpin RNA (shRNA) to downregulate AP-2 $\alpha$ protein expression in Apoe $^{-/-}$mice (Supplementary Figure S2B). AP- $2 \alpha$ shRNA lentivirus did not alter metabolic characters including TG, TC, BG, and blood monocyte counts (Supplementary Table S1). As depicted in Figure 3A, 3B, and 3E, AP-2 $\alpha$ shRNA treated mice had significantly higher lesion areas in the aorta and aortic arch than control shRNA treated mice. Aspirin significantly suppressed whole aortas and aortic arch lesion areas in Apoe $^{-/}$mice infected with control shRNA lentivirus, but had no significant suppression in Apoe $^{-/-}$ mice infected with AP- $2 \alpha$ shRNA lentivirus. Similarly, aspirin decreased the Oil Red staining of lipids in the aortic arch of control shRNA treated in $A p o e^{-/-}$mice but did not in AP-2 $\alpha$ shRNA lentivirus treated mice (Figure $3 \mathrm{C}, 3 \mathrm{D})$. These data demonstrate that AP- $2 \alpha$ is required for atherosclerotic plaque suppression by aspirin in vivo.

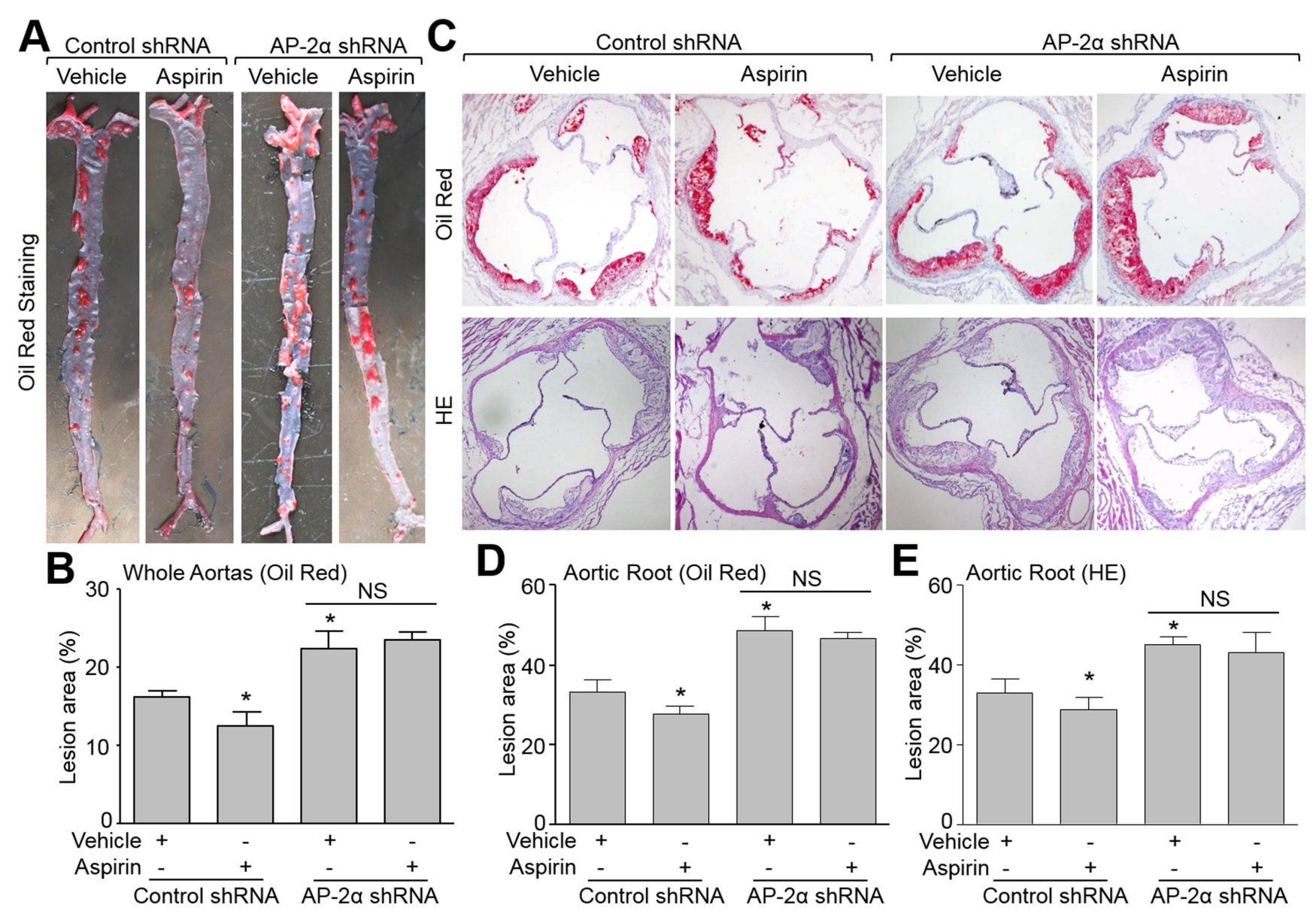

Figure 3: Deficiency of AP-2 $\alpha$ abolishes the suppressive effects of aspirin on aortic atherosclerotic lesion development in $\boldsymbol{A p o e}^{-/-}$mice. The protocol and experimental designs were described in Supplementary Methods and Figure S2A. A. Morphological analysis of atherosclerotic lesions in whole aortas by Oil Red staining. B. Quantitative data of atherosclerotic lesions. 10-15 mice in each group. ${ }^{*} P<0.05 v s$. control shRNA alone. NS indicates no significance. C. Morphological analysis of aortic roots by Oil Red or HE staining (original magnification X100). D. Quantitative analysis of atherosclerotic lesion size in aortic roots by Oil Red in C. E. Quantitative analysis of atherosclerotic lesion size in aortic roots by HE in C. Positive stained area is given as the percentage of the totally analyzed area of the aorta. $\mathrm{N}$ is $10-15$ in each group. ${ }^{*} P<0.05 v s$. control shRNA alone. NS indicates no significance. 
Knockdown of AP-2 $\alpha$ ablates the effects of aspirin on maintaining atherosclerotic plaque stability in Apoe $^{-/}$mice

We next determined the role of AP- $2 \alpha$ in aspirininduced atherosclerotic plaque stability using the carotid collar model of vulnerable plaque formation in Apoe mice treated with control or AP- $2 \alpha$ shRNA lentivirus. AP- $2 \alpha$ shRNA lentivirus -mediated RNA interference significantly inhibited AP- $2 \alpha$ protein expression in the plaque area of carotid arteries compared to control lentivirus (Supplementary Figure S2D and S2E). Vulnerable plaque sizes induced by collar placement were comparable in all treatment groups $A_{p o e^{-/}}$mice
(Figure 4A, 4B). Histological analysis revealed that aspirin increased the levels of $\alpha$-SMA and collagen in the plaque, and reduced the levels of lipid and CD68 in $\mathrm{Apoe}^{-/}$mice treated with control shRNA (Figure 4A, 4C). By calculating plaque vulnerable index, aspirin increased the plaque stability in $A p o e^{-/}$mice (Figure 4D). However, AP- $2 \alpha$ shRNA knockdown of AP- $2 \alpha$ induced significantly increased CD68 and lipid deposition as well as suppressed collagen and $\alpha$-SMA expression indicating highly vulnerable plaque formation (Figure 4A, 4C, 4D). Aspirin could not suppress plaque instability in the AP- $2 \alpha$ shRNA treated mice. These data demonstrate that AP- $2 \alpha$ is essential for atherosclerotic plaque stability induced by aspirin.

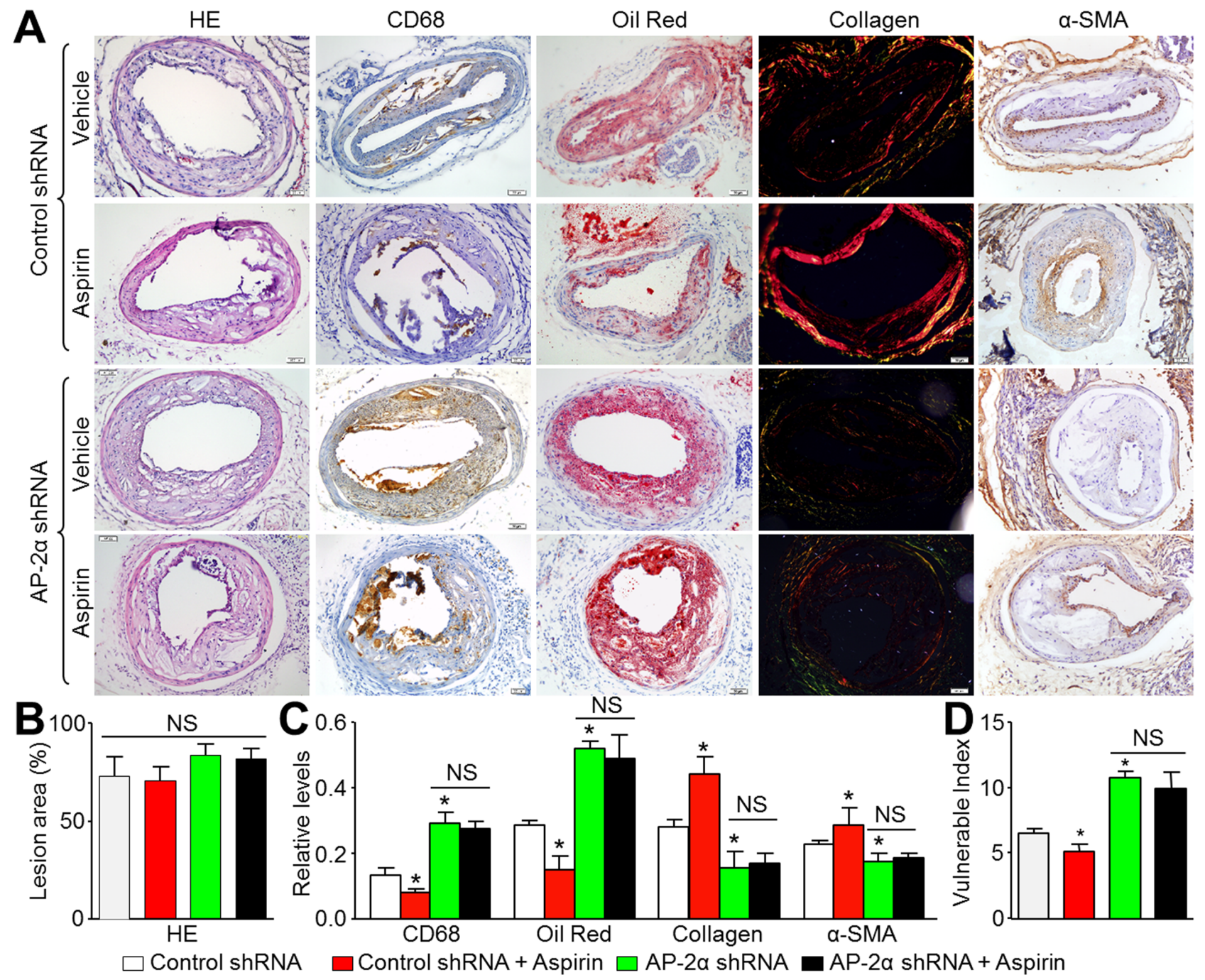

Figure 4: Aspirin increases carotid atherosclerotic plaque stability in $\mathrm{Apoe}^{-/}$mice via AP-2a. The protocol and experimental designs were described in Supplementary Methods and Figure S2C. A. Morphology of left common carotid arteries by HE staining, Oil Red staining for lipid content, picrosirius red staining of collagen, numbers of vascular smooth muscle cells by $\alpha$-SMA, and macrophages by CD68, respectively (original magnification X100). B. Quantitative data for sizes of atherosclerotic lesion in left common carotid arteries. C. Quantitative data for lipid content, collagen, VSMC number, and macrophages number. D. Vulnerability index was determined by using the ration of $\mathrm{CD}^{+} 8^{+}(\%)$ plus Oil Red (\%) to $\alpha$-SMA (\%) plus collagen (\%). N is $10-15$ in each group. ${ }^{*} P<0.05 v s$. control shRNA alone. NS indicates no significant difference. 


\section{Aspirin increases AP-2 $\alpha$ DNA-binding activity in VSMCs}

We next addressed the molecular mechanism whereby aspirin can reduce the atherosclerotic burden and promote plaque stability. We cultured human VSMCs with increasing doses of aspirin and quantified phosphorylated AP-2 $\alpha$. As shown in Figure 5A, the serine 219 phosphorylation of AP- $2 \alpha$ was increased by aspirin in a dose-dependent manner. To mimic the inflammatory microenvironment of vascular cells in atherosclerosis plaque, VSMCs were stimulated with tumor necrosis factor alpha $(\mathrm{TNF} \alpha)$ to induce oxidative stress. AP$2 \alpha$ DNA-binding activity was assayed by EMSA. As indicated in Figure 5B, aspirin increased AP-2 $\alpha$ DNAbinding activity in nuclear extracts from both resting and $\mathrm{TNF} \alpha$-stimulated endothelial cells, suggesting that aspirin functions as a potent AP- $2 \alpha$ activator in VSMCs.

\section{Aspirin via AP-2 $\alpha$ activation increases IkB $\alpha$ gene expression in VSMCs}

The NF-kB-mediated NAD(P)H oxidase upregulation and oxidative stress, which is determined by $\operatorname{IkB} \alpha$ [25], plays a critical role in atherosclerosis. Therefore, we hypothesized that aspirin via AP- $2 \alpha$ activation increases IkB $\alpha$ gene expression to suppress NF$\mathrm{kB}$-mediated $\mathrm{NAD}(\mathrm{P}) \mathrm{H}$ oxidase-derived ROS productions in VSMCs. We then examined the levels of $\operatorname{IkB} \alpha$, a regulator of inflammation. The association between AP$2 \alpha$ activation and I $\mathrm{B} \alpha$ gene upregulation was tested by CHIP assay (Supplementary Figure S3A), indicating that there is an AP- $2 \alpha$ binding site in the promoter/enhancer region of IкB $\alpha$ gene. In Figure 5C, TNF $\alpha$ dramatically
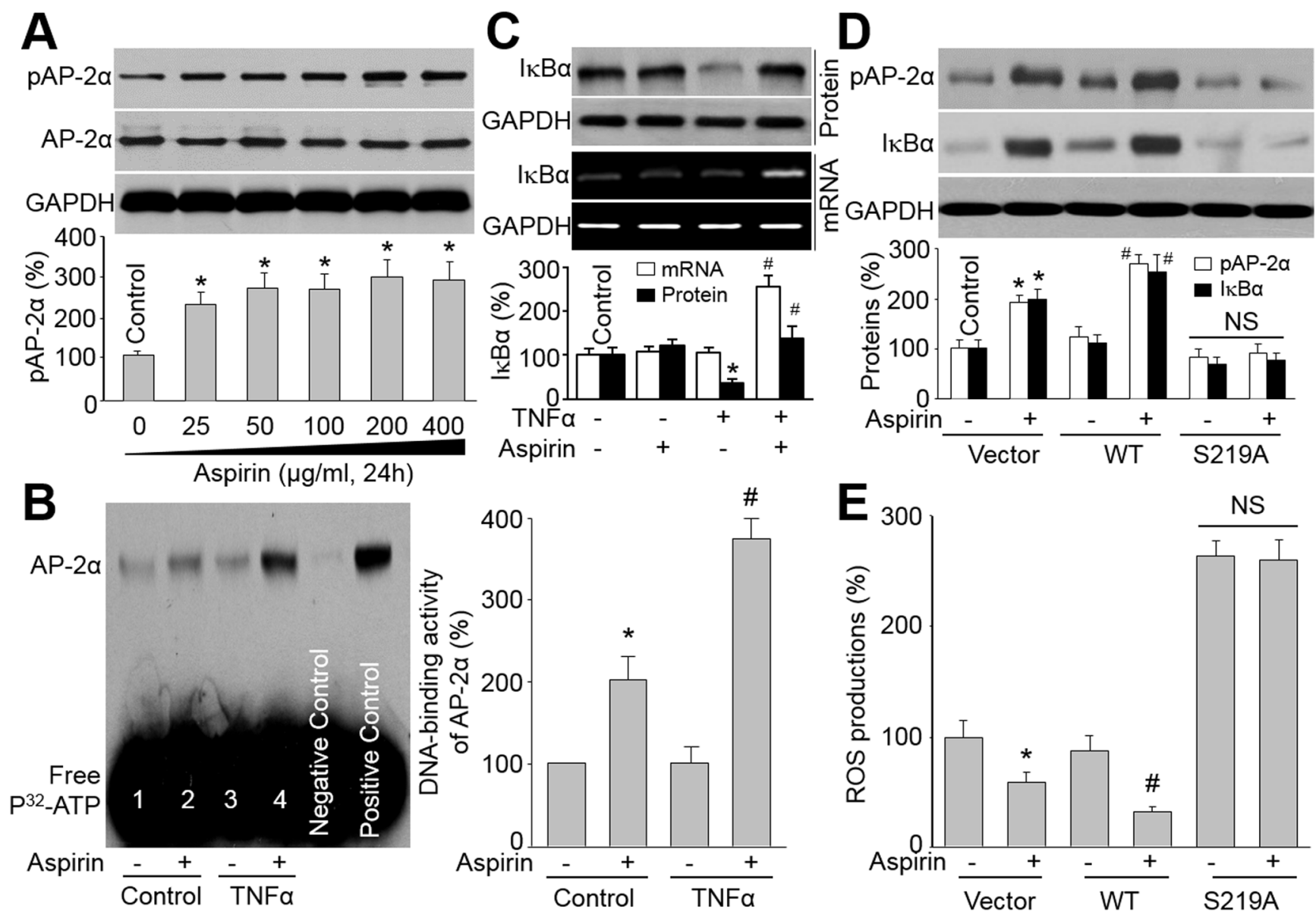

Figure 5: Aspirin via AP-2 $\alpha$ upregulates IkBa levels in VSMCs. A. Cultured VSMCs were treated with $25-400 \mu \mathrm{g} / \mathrm{ml} \mathrm{aspirin}$ (24 hours). Cell lysates were immunoblotted with anti-phosphorylated AP- $2 \alpha$ antibody. ${ }^{*} P<0.05$ vs. Control. (B and C) VSMCs were treated with TNF $\alpha(10 \mathrm{ng} / \mathrm{ml}, 24$ hours $)$ plus aspirin $(200 \mu \mathrm{g} / \mathrm{ml})$. Cells were subjected to detect AP-2 $\alpha$ DNA-binding activity by EMSA in B and the levels of IkBa protein and mRNA by Western blot or RT-PCR in C. ${ }^{*} P<0.05 v s$. control. ${ }^{\#} P<0.05 v s$. TNF $\alpha$ alone. (D and E) VSMCs were infected with adenovirus vector containing cDNA of WT-AP-2 $\alpha$ or S219A-AP-2 $\alpha$ for 48 hours. After that, cells were incubated with or without aspirin $(200 \mu \mathrm{g} / \mathrm{ml})$ for 24 hours. Cell lysates were harvested to assay protein level of IkBa by Western blot in D and ROS productions by DHE/HPLC in E. N is 3 in each group. ${ }^{*} P<0.05 v s$. Vector alone. ${ }^{\sharp} P<0.05$ vs. WT-AP-2 $\alpha$ alone. NS indicates no significant difference. 
decreased the IkB $\alpha$ protein level, while co-incubation of aspirin reversed $\mathrm{TNF} \alpha$-induced reduction of $\operatorname{IkB} \alpha$ protein levels. Importantly, aspirin also increased $\mathrm{IkB} \alpha \mathrm{mRNA}$ in TNF $\alpha$-treated cells, indicating that the upregulation of $\mathrm{IkB} \alpha$ protein by aspirin may be through gene transcription.

To determine if activated AP- $2 \alpha$ is required for aspirin-induced upregulation of $\mathrm{IkB} \alpha$, we infected endothelial cells with adenoviruses containing wild-type (WT) or mutant of AP-2 $\alpha$ by replacing serine 219 to alanine (S219A). As shown in Figure 5D, aspirin increased the level of pS219-AP-2 $\alpha$ in cells infected with plain vector or WT-AP-2 $\alpha$, but not in cells with overexpression of S219A-AP-2 $\alpha$ mutant. Compared to plain vector, WTAP-2 $\alpha$ further enhanced aspirin-stimulated $\mathrm{IkB} \alpha$ protein expression in cells. However, S219A-AP-2 $\alpha$ abolished the effects of aspirin on $\mathrm{IkB} \alpha$ protein expression in cells. Reversely, ROS production was not suppressed by aspirin in cells expressing S219A AP-2 $\alpha$ (Figure 5E), indicating that activated AP- $2 \alpha$ is required for aspirin's inhibitory effect on oxidative stress. In sum, activation of AP- $2 \alpha$, by serine 219 phosphorylation, is critical for suppression of oxidative stress by aspirin in VSMCs (Supplementary Figure S3B).

\section{Aspirin via AP-2 $\alpha$ enhances IkBa protein and reduces oxidative stress in $A_{p o e^{-/}}$mice}

The role of $\mathrm{AP}-2 \alpha$ on $\mathrm{IkB} \alpha / \mathrm{NF}-\mathrm{kB} / \mathrm{NAD}(\mathrm{P}) \mathrm{H}$ oxidase in mice was also investigated. In Figure 6A and $6 \mathrm{~B}$, aspirin dramatically increased $\mathrm{IkB} \alpha$ protein level, inhibited NF-kB DNA-binding activity, and reduced the levels of p47, Nox4 and 4-HNE in carotid arteries from Apo $^{-/}$- mice infected with control shRNA. The effects of aspirin on suppression of oxidative stress were further confirmed by detecting the levels of F2-isoprostanes, which was a non-invasive marker of oxidative stress [26], in urine and blood (Supplementary Figure S4A and S4B). Knockdown of AP- $2 \alpha$ by shRNA bypassed these alterations induced by aspirin.

\section{Aspirin increases AP-2 $\alpha$ phosphorylation and IkBa protein expression in humans}

Finally, to address if the conventional dose of aspirin activates AP- $2 \alpha$ and upregulates $\operatorname{IkB} \alpha$ protein level in humans, we assayed AP- $2 \alpha$ phosphorylation and $\mathrm{IkB} \alpha$ protein in humans. The compliance to aspirin treatment was assessed by determining the platelet cyclooxygenase 1 activity. As indicated in Figure 7A-7C, aspirin at the dose of $100 \mathrm{mg} /$ day remarkably reduced
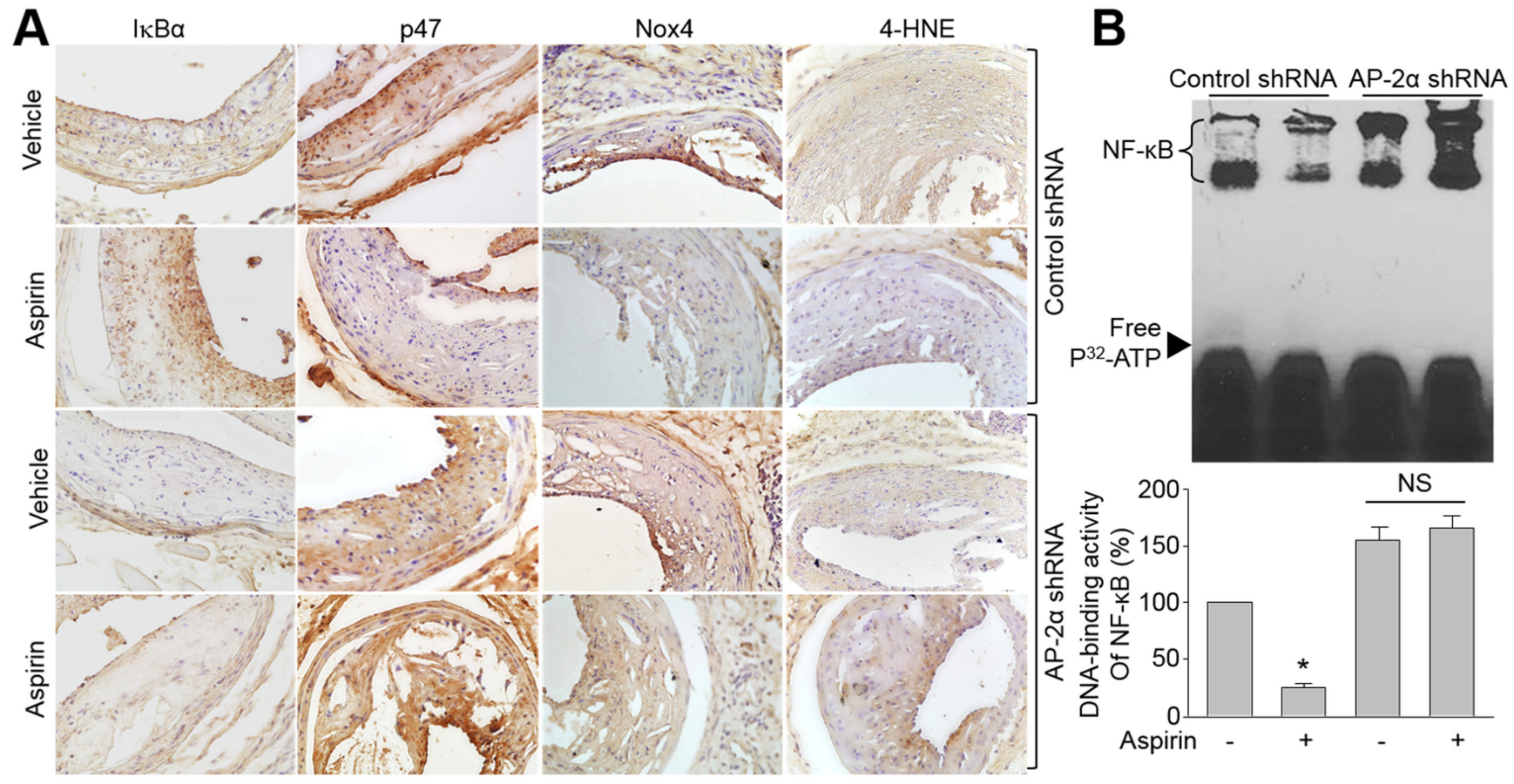

Figure 6: Knockdown of AP-2 $\alpha$ abolishes the effects of aspirin on IkB $\alpha$ gene expression, NAD(P)H oxidase protein expressions, and oxidative stress in $\mathbf{A p o e}^{-/}$mice with vulnerable atherosclerotic plaque. The protocol and experimental designs were described in Supplementary Methods and Figure S2C. A. Protein expressions of IkB $\alpha$, Nox4, p47, and 4-HNE by IHC staining were determined. The picture shown is a representative picture from 10-15 mice in each group. B. Quantitative analysis of NF-kB DNA-binding activity in mice carotid arteries assayed by EMSA. Data were expressed by mean $\pm \mathrm{SEM} . \mathrm{N}$ is $10-15$ in each group. ${ }^{*} P<0.05$ $v s$. control shRNA alone. NS indicates no significance. 
both the COX-1 activity and the plasma TXA2 level in human subjects, and inhibited ADP-induced platelet aggregation. As expected, the levels of $\mathrm{pAP}-2 \alpha$ and $\mathrm{IkB} \alpha$ protein in leucocytes were much higher in patients taking aspirin than those non-aspirin controls (Figure 7D). Due to probable interindividual differences, we also tested the levels of $\mathrm{pAP}-2 \alpha$ and $\mathrm{IkB} \alpha$ protein in the same person. Similarly, the levels of pAP- $2 \alpha$ and $\mathrm{IkB} \alpha$ protein were increased after aspirin administration, compared to those before aspirin treatment (Figure 7E). Collectively, these data demonstrate that aspirin at conventional dose is able to activate $\mathrm{AP}-2 \alpha / \mathrm{IkB} \alpha$ pathway in humans, revealing the high clinical relevance of our experimental observations.

\section{DISCUSSION}

In the present study, we have first provided the evidences to determine that AP- $2 \alpha$ is a novel target of aspirin, and to show the important role of AP- $2 \alpha$ in the development and instability of atherosclerotic plaque in all stages. In mice, aspirin suppressed the growth of atherosclerosis lesion and promoted the plaque stability. Importantly, all these effects of aspirin were abolished by knockdown of AP-2 $\alpha$ via genetic approaches. Thus, we

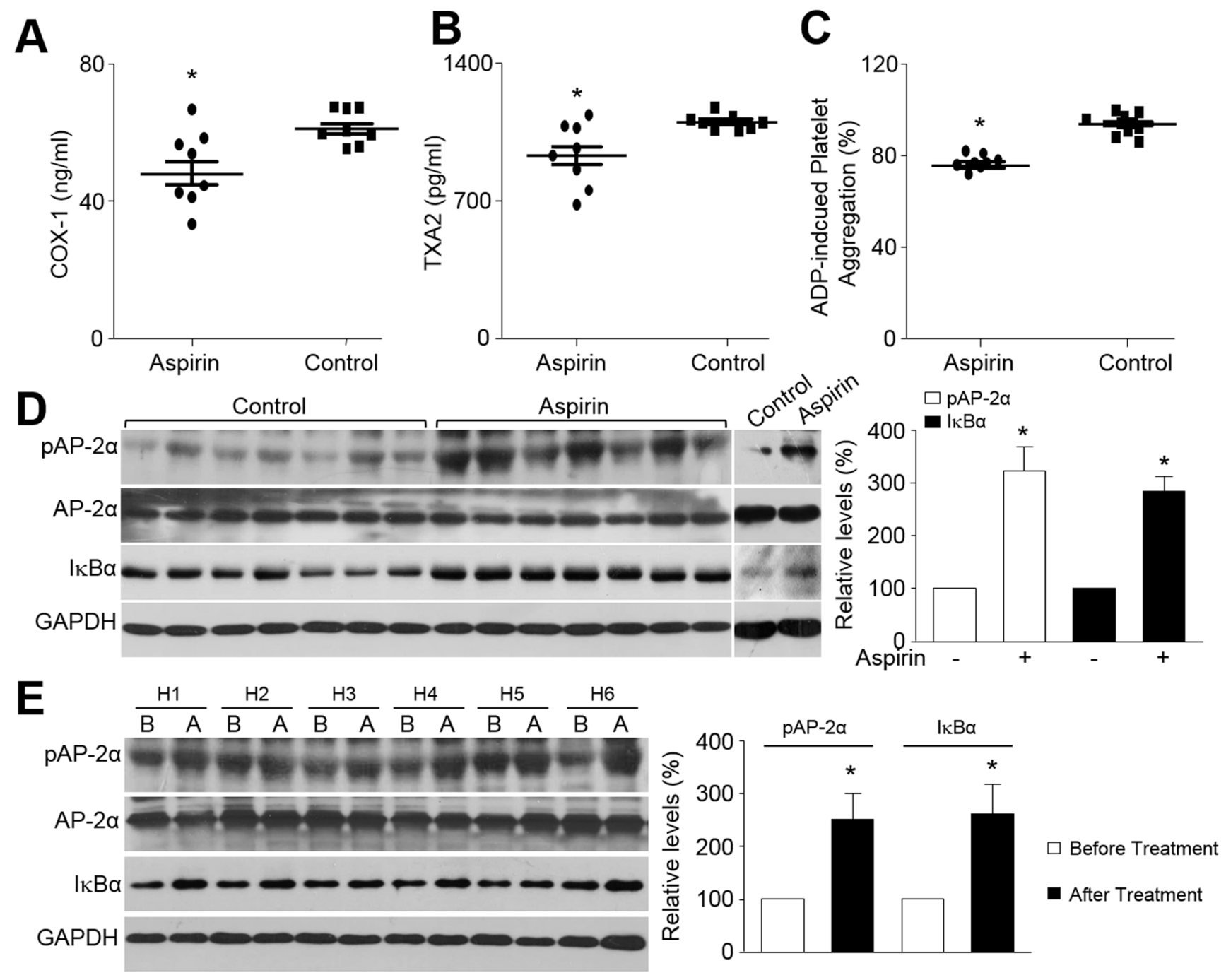

Figure 7: Aspirin activates AP-2 $\alpha$ and increases IkB $\alpha$ protein expression in humans. A.-D. The demographic data were shown in Supplementary Table S2. Blood were collected from human patients taking aspirin or not. Leucocytes were isolated from fresh blood and subjected to detect the COX-1 activity in A, the plasma TXA2 level in B, ADP-induced platelet aggregation in C, and the levels of phosphorylated AP- $2 \alpha$ protein and total IkB $\alpha$ protein in D. Eight human subjects are in each group. ${ }^{*} P<0.05 v s$. Control. E. The demographic data were shown in Supplementary Table S3. Six human subjects were recruited to taking aspirin (100 mg/day) for $4 \mathrm{weeks}$. Blood were collected before and after aspirin administration to detect the levels of phosphorylated AP- $2 \alpha$ protein and total IkB $\alpha$ protein by Western blot to detect. H, Human subject. B, Before aspirin treatment. A, After aspirin treatment. ${ }^{*} P<0.05 v s$. Before aspirin treatment. An unpaired or paired Student's $t$-test was applied for statistical comparisons between two groups. 
conclude that AP- $2 \alpha$ is required for aspirin to suppress atherosclerosis.

An important finding of this study is that aspirin via AP-2 $\alpha$ activation inhibits the growth and instability atherosclerotic plaques. We not only provided experimental evidences to indicate the action of aspirin to maintain the stability of advanced atherosclerotic plaque, but also identified a unique mechanism of aspirin on reducing acute coronary syndrome distinct from regular nonsteroidal anti-inflammatory drugs. It is well known that aspirin is one of the major preventive treatments against cardiovascular events to prevent vascular complications of atherosclerosis [27]. The traditional mechanism of action of aspirin is considered as inhibition of cyclooxygenases [20]. In this study, we observed that aspirin increased AP- $2 \alpha$ serine 219 phosphorylation in cells and in mice. Importantly, the beneficial effects of aspirin on the growth and the stability of atherosclerosis plaque were abolished by knockdown of AP-2 $\alpha$ via genetic approaches. Although it has been reported that AP- $2 \alpha$ modulates the expression of ATP-binding cassette transporter A1 gene, which is a rate-limiting factor for high-density lipoprotein biogenesis [28, 29]. Moreover, AP- $2 \alpha$ activation inhibits oxidative stress in human epithelial cells [30]. Our studies firstly indicate that AP- $2 \alpha$ is critical in the progression of atherosclerosis and activated by aspirin.

In this study, we uncovered that AP- $2 \alpha$ regulates IkBa gene expression. In vitro and in vivo knockdown of AP- $2 \alpha$ by shRNA and expression of mutant S219A AP- $2 \alpha$ reduced IkBa protein level. Under resting conditions, $\mathrm{IkB} \alpha$ protein binds to NF-kB in cytoplasm. Upon stimulation by cytokines, IkB $\alpha$ undergoes rapid phosphorylation, ubiquitinylation, and subsequent degradation by the $26 \mathrm{~S}$ proteasome, leading to NF-kB transactivation and consequent NAD(P)H oxidase expression [31]. Newly synthesized $\mathrm{IkB} \alpha$ is an important source to supplier to balance the degradation of IkB $\alpha$ protein by cytokines [32]. We and others have previously observed that cytokinesinduced NF-kB activation through $26 \mathrm{~S}$ proteasome dependent $\mathrm{IkB} \alpha$ degradation triggers oxidative stress and endothelial dysfunction $[15,33]$, which is a hallmark of early atherosclerosis. In fact, studies have reported that cardiovascular risk factors, such as hyperglycemia, enhanced $26 \mathrm{~S}$ proteasome functionality in the early stage, not in the late stage [34]. Combining these evidences, we expect that $26 \mathrm{~S}$ proteasome-dependent $\mathrm{IkB} \alpha$ degradation might play an important role in the initiation of atherosclerotic plaque.

A limitation of this study is that the dose of aspirin at 20 or $50 \mathrm{mg} / \mathrm{kg} /$ day in animal studies appeared to be high compared with the dosages prescribed for humans. Because of the species differences in pharmacokinetics and pharmacodynamics of drug between human and mammal animals, the dose of aspirin in mice is not applied to human usage base on a body scale-adjusted scale. According to Chodera's reports [35], we general used 10 as the coefficient of biotransformation for drugs between human and mouse. Thus, $50 \mathrm{mg} / \mathrm{kg}$ of aspirin in mice would correspond to about $0.35 \mathrm{~g}$ aspirin for a $70 \mathrm{~kg}$ human subject. This is an acceptable dose in human because the doses of aspirin in humans are 100 $\mathrm{mg}$ /day for anti-thrombosis and 300-600 $\mathrm{mg}$ /day for anti-pain or anti-fever, which were recommend by ESC Guidelines. Importantly, we have confirmed that aspirin at a conventional dose of $100 \mathrm{mg} /$ day increased AP- $2 \alpha$ phosphorylation in human peripheral blood leukocytes, revealing the clinical relevance of this study.

In summary, we identified a novel molecular mechanism by which aspirin via AP-2 $\alpha$ inhibits atherosclerosis in all stages. Thus, AP- $2 \alpha$ might be a therapeutic target to prevention atherosclerosis-associated diseases, such as stroke or myocardial infarction caused by rupture of advanced atherosclerotic plaque.

\section{MATERIALS AND METHODS}

A full description of materials and methods can be found in the online-only Supplementary Materials.

\section{Animal experiments and atherosclerotic lesion analysis}

The collar placement was used to induce atherosclerotic vulnerable plaque in Apoe $e^{-/}$mice. Briefly, a constrictive silastic tube was placed around the left common carotid artery near its bifurcation in mice fed with a high fat diet. Lentivirus infection was performed 4 weeks prior to aspirin administration $(5-50 \mathrm{mg} / \mathrm{kg} /$ day $)$. For analyzing the lesion area, the tissue was embedded in freezing medium and sectioned. Four consecutive sections were collected from each mouse and stained with Oil Red $\mathrm{O}$ or HE. The plaque vulnerable index in carotid artery was calculated according to the ratio of area I (Oil $\mathrm{Red}^{+}+$ $\left.\mathrm{CD}^{+} 8^{+}\right)$to area II $\left(\alpha-\mathrm{SMA}^{+}+\right.$Collagen $\left.^{+}\right)$.

\section{Patients and sample processing}

Patients, with comparable baseline characteristics including blood cell and platelet counts, were enrolled to take aspirin (100 mg/kg/day) for 4 weeks or 2-6 months with informed consent. All patients were observed to ingest aspirin daily by phone call. The patients who finished the whole treatment without aspirin resistance were calculated in clinical investigations. The platelet cyclooxygenase 1 activity, plasma thromboxane A2 level, and ADP-induced platelet aggregation were measured to determine the effects of aspirin treatment. Leucocytes were isolated from blood and subjected to perform western blot analysis of pAP- $2 \alpha$ and IkB $\alpha$. These protocols complied with the Management Rules of the Chinese Ministry of Health and were approved by the Ethical Committee of 
Shandong University Qilu Hospital.

\section{Statistical analysis}

Data were reported as mean $\pm \mathrm{SD}$ or SEM. One-way ANOVA followed by Tukey post-hoc tests or Bonferroni correction was used for multiple comparisons. For statistical comparison between two groups, we used an unpaired or paired Student's t-test. Two-sided $P$-value < 0.05 was considered as significant.

\section{ACKNOWLEDGMENTS}

This work was supported by National 973 Basic Research Program of China (2013CB530700 and 2015CB553600) and National Natural Science Foundation of China (81320108004, 81370411, 81470591, 81400195, and 31372409). This project was also sponsored by Program for New Century Excellent Talents in University (NCET-13-0351), the Scientific Research Foundation for the Returned Overseas Chinese Scholars, State Education Ministry, and Program of Clinical Investigation (Nanshan Group), Qilu Hospital, Shandong University (2014QLKY15). S.X.W. is a recipient of Qilu Professional Scholar of Shandong University.

\section{CONFLICTS OF INTEREST}

There is no conflict of interest.

\section{Author Contributions}

J.J.Y. and designed and conducted the experiments, analyzed data, P.L.,. F.W., W.J.L., H.M., and Y.C. partially performed some experiments and analyzed data. Z.M.M., Q.Z.L., and Q.S.P. gave a lot of helpful suggestions to this project. Y.Z. and S.X.W. designed and performed the experiments, analyzed data, wrote the manuscript, and convinced the whole project.

\section{REFERENCES}

1. Libby P. Inflammation in atherosclerosis. Nature. 2002;420:868-874.

2. Han Y ZS, Gong Y, Hou G, Li X, Li L. Serum cyclin-dependent kinase 9 is a potential biomarker of atherosclerotic inflammation. Oncotarget. 2016;7:18541862.

3. Zhao F, Satoda M, Licht JD, Hayashizaki Y, Gelb BD. Cloning and characterization of a novel mouse ap-2 transcription factor, ap-2delta, with unique DNA binding and transactivation properties. J Biol Chem. 2001;276:40755-40760.

4. Schorle H, Meier P, Buchert M, Jaenisch R, Mitchell PJ.
Transcription factor ap-2 essential for cranial closure and craniofacial development. Nature. 1996;381:235-238.

5. Zhang J, Hagopian-Donaldson S, Serbedzija G, Elsemore J, Plehn-Dujowich D, McMahon AP, Flavell RA, Williams T. Neural tube, skeletal and body wall defects in mice lacking transcription factor ap-2. Nature. 1996;381:238-241.

6. Shi D, Xiao X, Tian Y, Qin L, Xie F, Sun R, Wang J, Li W, Liu T, Xiao Y, Yu W, Guo W, Xiong Y, Qiu H, Kang T, Huang W, Zhao C, Deng W. Activating enhancer-binding protein-2alpha induces cyclooxygenase-2 expression and promotes nasopharyngeal carcinoma growth. Oncotarget. 2015;6:5005-5021.

7. Yue W ZX, Lin Y, Yang CS, Xu Q, Carpizo D, Huang H, DiPaola RS, Tan XL. Metformin combined with aspirin significantly inhibit pancreatic cancer cell growth in vitro and in vivo by suppressing anti-apoptotic proteins mcl-1 and bcl-2. Oncotarget. 2015;6:21208-21224. doi: 10.18632/ oncotarget. 4126.

8. Nemerovski CW, Salinitri FD, Morbitzer KA, Moser LR. Aspirin for primary prevention of cardiovascular disease events. Pharmacotherapy. 2012;32:1020-1035.

9. Cayatte AJ, Du Y, Oliver-Krasinski J, Lavielle G, Verbeuren TJ, Cohen RA. The thromboxane receptor antagonist s18886 but not aspirin inhibits atherogenesis in apo e-deficient mice: Evidence that eicosanoids other than thromboxane contribute to atherosclerosis. Arterioscler Thromb Vasc Biol. 2000;20:1724-1728.

10. Tous M, Ferre N, Vilella E, Riu F, Camps J, Joven J. Aspirin attenuates the initiation but not the progression of atherosclerosis in apolipoprotein e-deficient mice fed a high-fat, high-cholesterol diet. Basic Clin Pharmacol Toxicol. 2004;95:15-19.

11. Hawley SA, Fullerton MD, Ross FA, Schertzer JD, Chevtzoff C, Walker KJ, Peggie MW, Zibrova D, Green KA, Mustard KJ, Kemp BE, Sakamoto K, Steinberg GR, Hardie DG. The ancient drug salicylate directly activates amp-activated protein kinase. Science. 2012;336:918-922

12. Ou HC, Lee WJ, Wu CM, Chen JF, Sheu WH. Aspirin prevents resistin-induced endothelial dysfunction by modulating ampk, ros, and akt/enos signaling. Journal of vascular surgery. 2012;55:1104-1115.

13. Sung JY, Choi HC. Aspirin-induced amp-activated protein kinase activation regulates the proliferation of vascular smooth muscle cells from spontaneously hypertensive rats. Biochem Biophys Res Commun. 2011;408:312-317.

14. Lissa D, Senovilla L, Rello-Varona S, Vitale I, Michaud M, Pietrocola F, Boileve A, Obrist F, Bordenave C, Garcia P, Michels J, Jemaa M, Kepp O, Castedo M, Kroemer G. Resveratrol and aspirin eliminate tetraploid cells for anticancer chemoprevention. Proc Natl Acad Sci U S A. 2014;111:3020-3025.

15. Wang S, Zhang M, Liang B, Xu J, Xie Z, Liu C, Viollet B, Yan D, Zou MH. Ampkalpha2 deletion causes aberrant expression and activation of nad(p)h oxidase and 
consequent endothelial dysfunction in vivo: Role of $26 \mathrm{~s}$ proteasomes. Circ Res. 2010;106:1117-1128.

16. Dong Y, Zhang M, Wang S, Liang B, Zhao Z, Liu C, Wu M, Choi HC, Lyons TJ, Zou MH. Activation of amp-activated protein kinase inhibits oxidized ldl-triggered endoplasmic reticulum stress in vivo. Diabetes. 2010;59:1386-1396.

17. Wang S, Zhang C, Zhang M, Liang B, Zhu H, Lee J, Viollet B, Xia L, Zhang Y, Zou MH. Activation of amp-activated protein kinase alpha2 by nicotine instigates formation of abdominal aortic aneurysms in mice in vivo. Nat Med. 2012;18:902-910.

18. Halvorsen S, Andreotti F, ten Berg JM, Cattaneo M, Coccheri S, Marchioli R, Morais J, Verheugt FW, De Caterina R. Aspirin therapy in primary cardiovascular disease prevention: A position paper of the european society of cardiology working group on thrombosis. J Am Coll Cardiol. 2014;64:319-327.

19. Jiang H, Huang S, Li X, Li X, Huang S, Zhang Y, Chen ZY. Endothelial tyrosine kinase receptor $\mathrm{b}$ prevents vecadherin cleavage and protects against atherosclerotic lesion development in apoe-/- mice. Oncotarget. 2015;6:3064030649. doi: 10.18632/oncotarget.5855.

20. Kraus S, Naumov I, Shapira S, Kazanov D, Aroch I, Afek A, Eisenberg O, George J, Arber N, Finkelstein A. Aspirin but not meloxicam attenuates early atherosclerosis in apolipoprotein e knockout mice. The Israel Medical Association journal. 2014;16:233-238.

21. Bentzon JF, Otsuka F, Virmani R, Falk E. Mechanisms of plaque formation and rupture. Circ Res. 2014;114:18521866.

22. von der Thusen JH, van Berkel TJ, Biessen EA. Induction of rapid atherogenesis by perivascular carotid collar placement in apolipoprotein e-deficient and low-density lipoprotein receptor-deficient mice. Circulation. 2001;103:1164-1170.

23. Spagnoli LG, Bonanno E, Sangiorgi G, Mauriello A. Role of inflammation in atherosclerosis. Journal of nuclear medicine. 2007;48:1800-1815.

24. Dong M, Yang X, Lim S, Cao Z, Honek J, Lu H, Zhang C, Seki T, Hosaka K, Wahlberg E, Yang J, Zhang L, Lanne T, Sun B, Li X, Liu Y, Zhang Y, Cao Y. Cold exposure promotes atherosclerotic plaque growth and instability via ucp1-dependent lipolysis. Cell Metab. 2013;18:118-129.

25. Malanga D, De Marco C, Guerriero I, Colelli F, Rinaldo N, Scrima M, Mirante T, De Vitis C, Zoppoli P, Ceccarelli M, Riccardi M, Ravo M, Weisz A, Federico A, Franco R, Rocco G, Mancini R, Rizzuto A, Gulletta E, Ciliberto G, Viglietto G. The akt1/i1-6/stat3 pathway regulates growth of lung tumor initiating cells. Oncotarget. 2015;6:4266742686. doi: 10.18632/oncotarget.5626.
26. Halliwell B, Lee CY. Using isoprostanes as biomarkers of oxidative stress: Some rarely considered issues. Antioxid Redox Signal. 2010;13:145-156.

27. Sutcliffe P, Connock M, Gurung T, Freeman K, Johnson S, Ngianga-Bakwin K, Grove A, Gurung B, Morrow S, Stranges S, Clarke A. Aspirin in primary prevention of cardiovascular disease and cancer: A systematic review of the balance of evidence from reviews of randomized trials. PLoS One. 2013;8:e81970.

28. Iwamoto $\mathrm{N}$, Abe-Dohmae $\mathrm{S}, \mathrm{Lu} \mathrm{R}$, Yokoyama $\mathrm{S}$. Involvement of protein kinase $\mathrm{d}$ in phosphorylation and increase of DNA binding of activator protein 2 alpha to downregulate atp-binding cassette transporter a1. Arterioscler Thromb Vasc Biol. 2008;28:2282-2287.

29. Iwamoto $\mathrm{N}$, Abe-Dohmae S, Ayaori M, Tanaka N, Kusuhara M, Ohsuzu F, Yokoyama S. Atp-binding cassette transporter al gene transcription is downregulated by activator protein 2alpha. Doxazosin inhibits activator protein 2alpha and increases high-density lipoprotein biogenesis independent of alpha1-adrenoceptor blockade. Circ Res. 2007;101:156-165.

30. Yu L, Hitchler MJ, Sun W, Sarsour EH, Goswami PC, Klingelhutz AJ, Domann FE. Ap-2alpha inhibits c-myc induced oxidative stress and apoptosis in hacat human keratinocytes. Journal of oncology. 2009;2009:780874.

31. Karin M, Ben-Neriah Y. Phosphorylation meets ubiquitination: The control of nf- [kappa]b activity. Annu Rev Immunol. 2000;18:621-663.

32. Mathes E, O’Dea EL, Hoffmann A, Ghosh G. Nf-kappab dictates the degradation pathway of ikappabalpha. EMBO J. 2008;27:1357-1367.

33. Xiao L, Liu Y, Wang N. New paradigms in inflammatory signaling in vascular endothelial cells. Am J Physiol Heart Circ Physiol. 2014;306:H317-325.

34. Liu H, Yu S, Xu W, Xu J. Enhancement of 26s proteasome functionality connects oxidative stress and vascular endothelial inflammatory response in diabetes mellitus. Arterioscler Thromb Vasc Biol. 2012;32:2131-2140.

35. Chodera A, Feller K. Some aspects of pharmacokinetic and biotransformation differences in humans and mammal animals. Int J Clin Pharmacol Biopharm. 1978;16:357-360. 